\title{
Transformation: From a Glimpse to Observation-The Emergence of Conceptive Ideality in Contemporary Photography
}

\author{
Zhisheng Xin \\ College of Art and Design, Wuhan Institute of Technology, Wuhan 430205, China
}

\begin{abstract}
In the history of artistic photography, from the decisive moment put forward by the French photographer Henri Cartier-Bresson to "Sleeping by the Mississippi" by American Alec Soth, photography itself has gone through a period from grasping the moment to a more subtle observation, from a $135 \mathrm{~mm}$ film to an $8 \times 10$ large format camera, it is evident that a transformation has already underway in contemporary photography. This paper starts with the history of contemporary artistic photography, followed by analyzing the cause of the transformation and combining examples of large format artists to study how conceptive ideality was placed into their works. Therefore, it concludes the main characteristics of the conceptive ideality in contemporary photography.
\end{abstract}

KEYWORDS: contemporary photography, artistic photography, conceptive ideality, large format photography

\section{Introduction of Contemporary Photography}

Contemporary photography is considered the photographs made from the 1950s to now, and it aims to convey and express a specific content instead of making a profit. Moreover, from the perspective of time, we can define that contemporary photography is our time's art, and it is yet to be concluded. In "Camera Lucida: Reflections on Photography," Roland Barthes stated that "The photograph does not necessarily say what is no longer, but only and for certain what has been [1]", only as in contemporary photography means what has been just now. In "On Photography," Susan Sontag said that "Photographed images do not seem to be statements about the world so much as pieces of it, miniatures of reality that anyone can make or acquire. [2]" Contemporary photography can be recognized as the mirrors that reflect our own lives; it has a certain level of existence, it is the proof of what has happened, represents "this existed once before." Furthermore, as the world is dynamic and ever-changing, contemporary photography is at coherence with it. Other than that, contemporary photography also can be seen as the extension of our thoughts about the world, and it can also provide a different perspective of the ways 
we see things. However, talking about photography one must take the audience into account. So, contemporary photography work is usually an open proposition. There is no accurate answer to that. Only how you perceive it and what triggers you matters.

\section{Overview of History and Status in Contemporary Photography}

For contemporary photography, it can be roughly considered from the era of the ending of world-war-II to the present. And the inception of subtle observation way of large-format photography initiated at that time. The key photographic style is in the black and white, and the mainstream rejected colored photography. It only recognized black and white photography as a serious and formal kind of photography. In that time period, taking a photo would take sophisticated measurements of the light composition, and the limit of the film roll is about 35; other than that, focusing the lens on the subject also requires years of practice to do it swiftly and smoothly. Therefore, the photographers of that time consider more about the formality of visual effect during focusing, capturing and stabilizing the quality of the photo and laid great stress on the credit of authenticity in photography, hance the authenticity of photography is at its all-time high and people believe it when they see it. Contemporary photographers first emerge in both America and Europe. In Europe, a couple, Bernd and Hilla Becher's work laying the foundations contemporary photography, and their work was deeply influenced by August Sander's objective way of observing, and their artistic approach inherited the way he catalogs people and divide them, laying the foundations of the typology school of photography and provided an example of how photography work with other subjects such as field investigation and anthropology. The couple Bernd and Hilla Becher also founded the Dusseldorf School of photography, which cultivated the following artists such as Thomas Struth and Thomas Ruff and, most importantly, Andreas Gursky who have exerted massive influence on the objective ways of observation and shaped today's contemporary photography. In America, at the birth of contemporary photography, the word landscape only means the typical scenery like mountains and rivers, until the iconic photographer of contemporary photography Stephen Shore emerged; his work "Uncommon Places” was exhibited in MoMa in 1976, which marked the recognition of the colored photography. There is one other photographer who pushed the course of this action, William Eggleston. The pieces of his colored photography artworks were exhibited by MoMa right after the year Stephen Shore's exhibition. Besides their role in shifting the mainstream black and white to colored photography, they helped redefine the word landscape in photography. They redirected their focus on more living scenes, which leads back to a form of photography, "New Topographic: Photographs of a Man-altered Landscape," and continued and extended it. Finally, what makes photography contemporary is that the conceptual elements which were put into it that acts in the shifting ways of expressing and storytelling in photography[3]. From grasping the moment and capturing the reality, Andreas Gursky's most famous work, the "Rhein II," can be seen as one of the most defining work through digital technology to alter the photographs and convey a completely different meaning of what it supposed to 
be. By and large, Contemporary photography has the following turning points. First, it turned from 135mm film to a larger format; second, it shifted from black and white photograph to colored photograph, and most importantly, it changed the way of observing, form a simple clip to a careful observation, which creates the opportunity for photographers to be more conceptual in their artwork. Furthermore, the photo's structure, usage along with the influence of Bernd and Hilla Becher's modified the contemporary photography into sophisticated, controlled and prepared artwork[4].

\section{How Conceptive Ideality Exhibits in Contemporary Photography}

\subsection{From the Authenticity in Photography}

As mentioned before, the photograph itself represents of existence as, "it existed once." Therefore, we tend to believe that it is authentic for whatsoever is on a photograph when we observe it, and that is how contemporary photography exhibits the artist's conceptive ideality. By forging and altering the photograph, we can create an interesting paradox that something that was not supposed to exist yet exist on the photograph and everything looks perfectly sane. Here, we will take Andreas Gursky's most famous work, the "Rhein II" as an example (Fig.1).

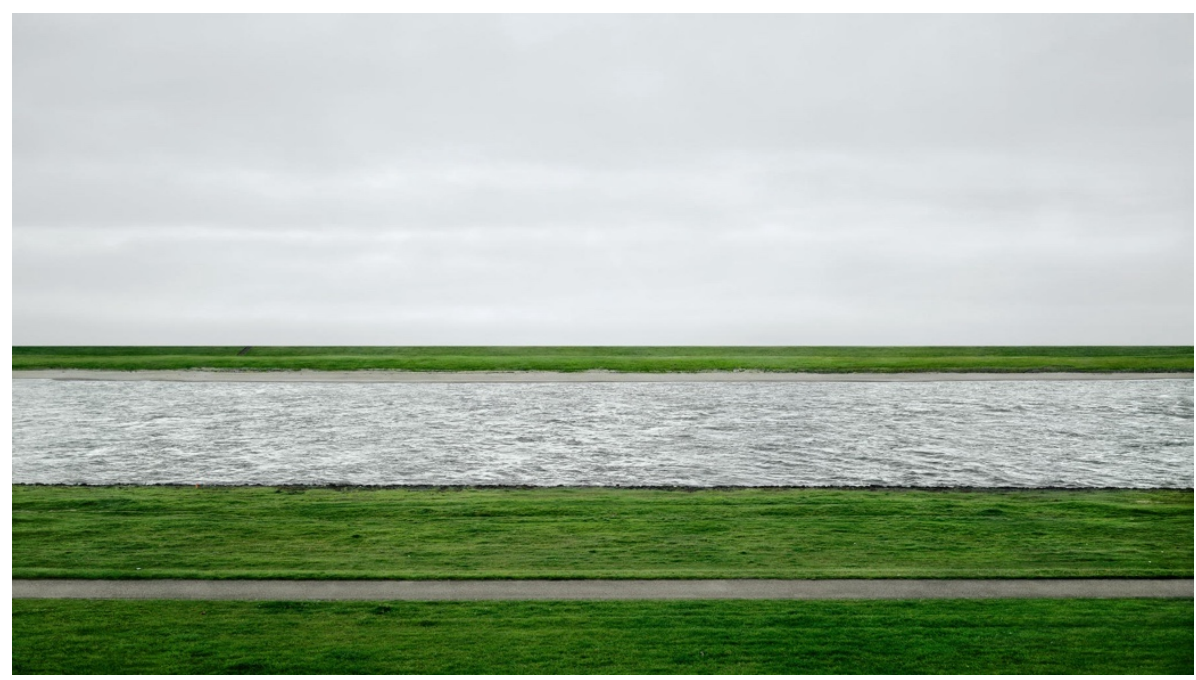

Figure. 1 "Rhein II” by Andreas Gursky

1. The artwork represent Rhein river, and we can describe it as a photograph with pristine natural beauty. We cannot see any human footprints in this photograph, and one can enjoy the purity of nature as represented in this photograph. Some might think that it is a well-shot landscape scenery. That 
is the average audience's thought. Then we go more in-depth into the professional audience level. This photograph is taken at the Rhein river but photoshopped to wipe out all human existence and traces. That is why we perceive nature first. What the artist is really trying to convey is that this empty land combine with his imagination of this place without human activities. Once this creativity is understood, a huge contrast was formed, and we realized what we thought was real is just an illusion. By altering of the photograph makes it look like the exact opposite of what was before, and by doing so, the artist acquired the reality by using the authenticity nature of photography. He creates a paradox for audiences to question what is real and what is not.

However, besides creating a paradox, another way of using a photograph's authenticity is to be sophisticatedly prepare for everything. Here we take Jeff Wall's artwork "Dead Troops Talk," for example.

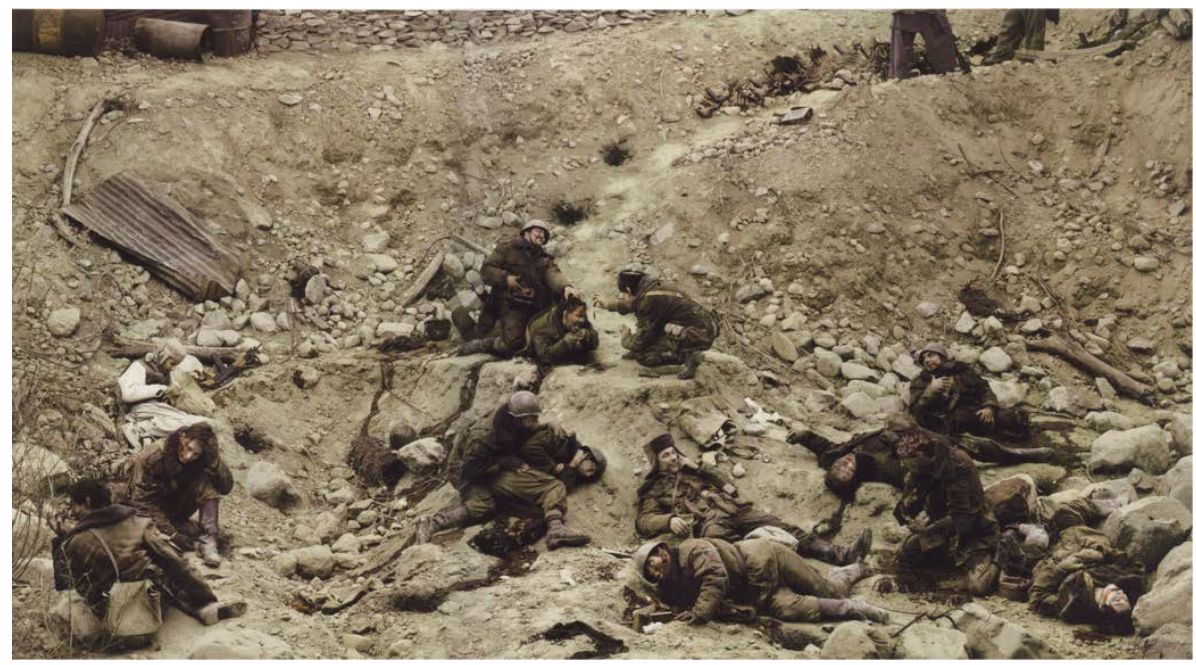

Figure. 2 “Dead Troops Talk” by Jeff Wall

The artist used the filming industry's approach to elaborately design the whole layout, including the makeup on actor's faces and their gestures. By a large amount of observing and analyzing, instead of just shooting them, he achieved the results that he wishes to convey and replant it into his own scenes. Therefore, we can say that what was presented in his photograph has a reason to be there. His photograph can be considered a highly compressed information vessel or an article with a great depth. On the one hand, he practically faked all the aspects of the photograph, and it can be reckoned that it is all scheduled beforehand, but on the other hand, what he arranged in the photo was a very accurate reflection of the real war, and he used the camera as the medium to let the audience think that it has all happened before which again serves his purpose of expression. This selected reality sometimes is more 
authentic than the exact real scenario. It is still a photograph with filtered information, and all that's left would combine to amplify the artist's intention, in reality, there is very little chance to capture such purposed and inclusion-free photograph. The artist creates the scene to reflect on reality and use this unique format to verify its authenticity as a symbol of what has happened, which combines to form the conceptive ideality in his work.

From Jeff Wall's work, we now understand the mechanism of the film-making category of artistic photography. This way of photographing is not unique it has being also being used by Chinese artist Wang Qing-song, and now we will combine Wang's artwork "Work, Work, Work" (Fig.3) to analyze how the mechanism was put into action.

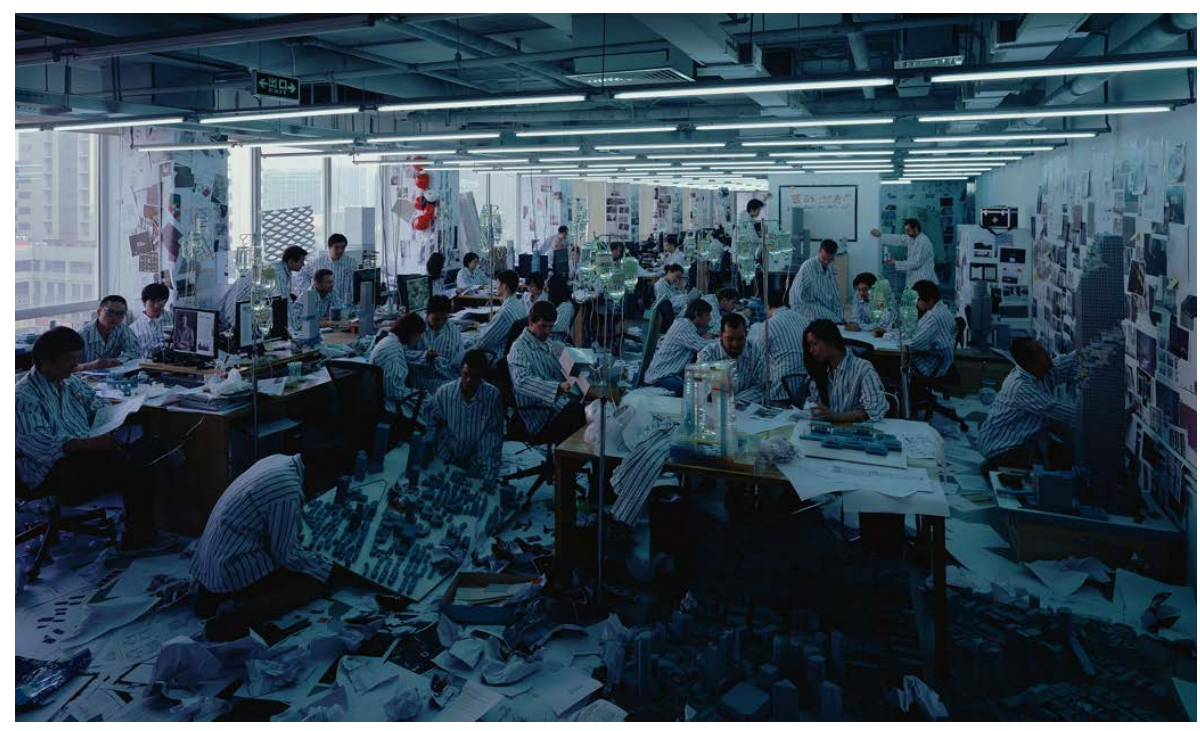

Figure. 3 “Work, Work, Work” by Wang Qingsong

This artwork was created in 2012. At that time in China, the real estate business was booming, and everybody was always working extra hours, in the factory or the office building, to fulfill the heavy workload. The picture was taken inside an environment laid out like an office building, the scene looks very messy, and it is the real estate complex building model and some other paperwork all over the floor, all the characters are dressed in Chinese patients' gown, and some of them are on the prescribed medical drip. Moreover, from the red helmet on the wall, combined with the building model, we can deduce that this is an office of the real-estate construction site that is currently expediting the project. From the subjects appeared in the photo, the artist constructed recognizable surroundings in our subjective knowledge. Each object indicates a message, and just like reading a novel, we read it and put it together. In this work, the patient's gown represents a status of sickness, 
ISSN 2618-1568 Vol. 2, Issue 9: 88-95, DOI: 10.25236/FAR.2020.020916

the real-estate model indicates the background of this photograph, combing the environment and other indications, it is easy to conclude that the artist is trying to criticize this social phenomenon of booming real-estate which leads to the capital pouring in and eventually overloading the employee in the industry. Like Jeff Wall, Wang also controlled all the pieces that appeared on the scene, however Wang is leaning more to a semiology indication. He combines the things which have representing characteristics and convey a prominent visual indication, while Jeff Wall is more leaning towards covering the details which resembles more to the reality.

\subsection{From the abstract storytelling}

As stated above, contemporary photography came from the era when photography's authenticity is considered as capturing the moment. Photographers use the camera like gun barrels and point it to all kind of people to capture a real and authentic scene. However, in contemporary photography, this way of verifying authenticity has changed. The documentary photography from insisting the objective document and record shifted to a personal document. Here we take American photographer Alec Soth's work "Sleeping by the Mississippi" as an example (Fig.4).

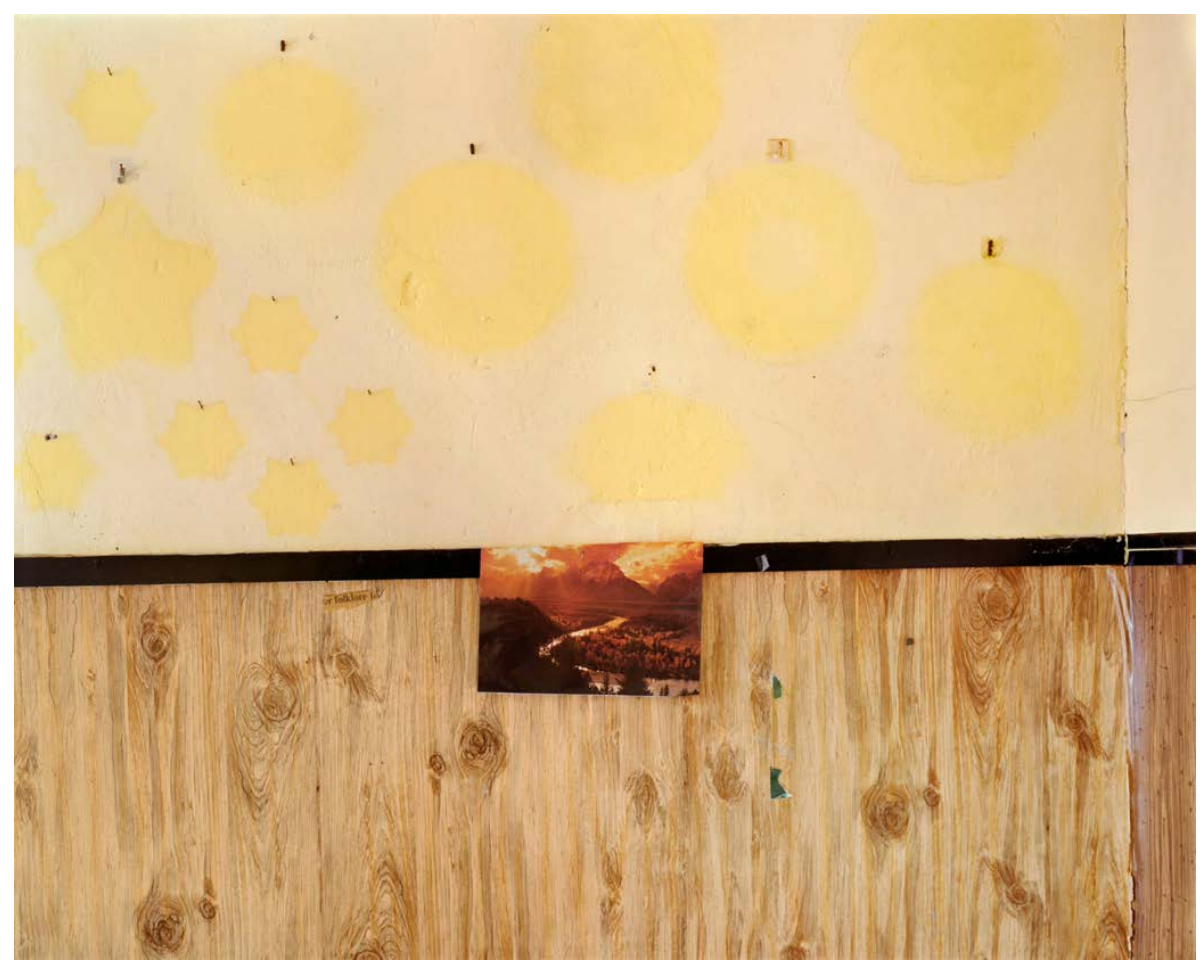

Published by Francis Academic Press, UK 
ISSN 2618-1568 Vol. 2, Issue 9: 88-95, DOI: 10.25236/FAR.2020.020916

Figure.4 "Cape Girardeau" in "Sleeping by the Mississippi" by Alec Soth

Sleeping by the Mississippi is a photo album containing more than one photograph that described the scenery that Alec Soth saw during his drive along the Mississippi River. What he captured was his own reality instead of being completely objective. It is all about what he feels and remember in his thoughts. He reconstructed the Mississippi river out of his memory, building his own Mississippi River. Suppose we thought of traditional documentary photography as an article and how Alec Soth photographs is like a poem filled with his imagination of the area and the place. The photographs in the series of Sleeping by the Mississippi do not pose an actual connection linearly but seems to be connected in the deeper level of pure emotions and sub-conscious, reaching in the loneliness and desire, failure and dream of the midland America. He took various subjects, from the aircraft fanatic living in the houseboat to the African American Woman sitting on the red couch. All sorts of photographed subjects formed a dotted narrative, which spreads the photos around the narrative structure and leaves an open blank for viewers to fill in, instead of linearly describing an event. This half-open space of photographs that was left behind gives the imagination space and opportunity for the audience to interpret in many other ways. Furthermore, a resemblance characteristic in the elements appears on the photographs like Jeff Wall and Wang Qingsong's work. From Fig,4 "Cape Girardeau," we see a wall with a picture of a valley, which leads people to wonder which valley is it and why this photo is there. Moreover, as we looked up the in other areas of the photograph, we see many needle holes on the wall, which makes me wonder if this wall was full of scenery pictures at certain time and if there were, then where are they now? The trails that were expressed in the photograph leave behind an open space for hypothesis.

\section{Conclusion}

The conceptive ideality in contemporary photography is exhibited in the subjects that appear on the photograph and often carry a semiotic characteristic. The subjects act as in its real physical form and correspond to personal thoughts of the audiences, which provides a pathway for expression and speculations. Considering the medium nature of the camera, we use what is physically present to reconstruct an environment that has not really happened yet in order to filter the unnecessary information in the background and to photograph a staged truth using the authentic nature of the medium to build a paradox, which leads the audience's thoughts from the work's representation into the fundamental essence of the artwork.

As we consider more elements of photographing, we improved from only capturing a scene to a more controlled and definitive capturing level. We reformed from grasping the moment to creating the moment. It both ends with a click of the camera but a very different level of thinking and orchestrating. 
ISSN 2618-1568 Vol. 2, Issue 9: 88-95, DOI: 10.25236/FAR.2020.020916

\section{References}

[1] Roland Barthes, translated by Richard Howard (1981). Camera Lucida: Reflections on Photography, Hill and Wang Press, New York

[2] Susan Sontag, Translated by Canran Huang(2018). On Photography. Shanghai Translation Publishing House

[3] Zhi Zhao(2019). Indicative iconography - Figurative imagery in contemporary photography. Art Observation, vol.8, p.79-80.

[4] Xianbiao Liu, Zhenguan Wang(2019). Study of the Dusseldorf School of Photography. Songs Bimonthly, vol.5, p.117-119. 